\title{
Reconstructed 3D models of digestive organs of developing Atlantic cod (Gadus morhua) larvae
}

\author{
Yuko Kamisaka • Ivar Rønnestad
}

Received: 18 June 2010/ Accepted: 23 September 2010/Published online: 20 October 2010

(C) The Author(s) 2010. This article is published with open access at Springerlink.com

\begin{abstract}
Six 3D models of the digestive system during ontogeny were reconstructed from histological sections of Atlantic cod larvae. The 3D models clearly visualize the following features: folding of the gut rotation; subdivision of digestive tract into foregut, midgut, and hindgut by sphincters; development of stomach and pyloric caeca from $39 \mathrm{dph}$; location of entrances of bile and pancreatic ducts in the medial plane of the anterior midgut; ontogeny of pancreas from a compact organ to an elongated and branched (but not diffuse) organ along the posterior midgut; one dominant islet of Langerhans until $39 \mathrm{dph}$ and several smaller satellite islets also visible from $53 \mathrm{dph}$; the relatively large volume of the anterior midgut that probably increases residence time of ingested food mixing with secretions from pancreas and bile. Calculated volumes of each digestive organ demonstrate allometric changes during ontogeny. Interactive 3D models are available as QuickTime format downloadable files.
\end{abstract}

\section{Introduction}

Atlantic cod (Gadus morhua) is historically a very important species in fisheries and has recently also become a promising species for aquaculture in the North Atlantic

Communicated by R. Thiel.

Electronic supplementary material The online version of this article (doi:10.1007/s00227-010-1554-x) contains supplementary material, which is available to authorized users.

Y. Kamisaka $(\bowtie) \cdot$ I. Rønnestad

Department of Biology, University of Bergen, P.O. Box 7800, 5020 Bergen, Norway

e-mail: yuko.kamisaka@bio.uib.no region (Brown et al. 2003; Engelsen et al., 2004; Rosenlund and Halldórsson 2007). However, larviculture of Atlantic cod is more complicated than for example production of Atlantic salmon (Salmo salar) since this species hatches from small pelagic eggs and requires live feed such as rotifers and Artemia in the early larval stage (MangorJensen et al. 2007).

Many of the limiting factors in Atlantic cod production appear to be related to factors involving the digestive system. This includes digestive processing capacity, gut transit, feed formulation and ingredient digestibility, early weaning onto microdiets, interactions between feeds and bacteria in the digestive tract. In order to understand the digestive process in larval cod better, many studies have described the morphological and histological development of digestive organs and development of digestive capacity, monitoring digestive enzymes and hormones during the early life stages (Kjørsvik et al. 1991; Pedersen and FalkPetersen 1992; Hunt von Herbing et al. 1996; Hamlin et al. 2000; Perez-Casanova et al. 2006; Kvåle et al. 2007; Wold et al. 2008, 2009). In most cases, natural zooplankton were used as live prey or larvae were reared in small experimental environment/rearing tanks. Studies of larvae fed rotifers and Artemia at a commercial cod hatchery provide more realistic information relevant to real features of masscultured larvae in industrial scale.

The morphology and the spatial organization of the digestive organs can be a challenge to understand on the basis of 2D histological sections or drawings, particularly when the larvae develops and the elongated gut becomes more coiled in the peritoneal cavity. It is also difficult to understand the development and organization of the developing and growing pancreas. We used 3D rendering and analysis software (Imaris, Bitplane AG, Zurich, Switzerland) in order to reconstruct 3D models of digestive 
organs from histological serial sections at different developmental stages of Atlantic cod larvae reared in a commercial hatchery. The final images include any combination of the organs and organ surfaces, and the models can be freely rotated in a computer allowing visualization of the models from any angle. A further aim was to acquire baseline volumetric and surface data from the digestive organs during ontogeny to study morphometric scaling of the digestive system based on the change of the relative proportion of different organs. This may provide a rough indicator for changes in the total delivery capacity of the digestive system to match the changing metabolic and anabolic demands as the cod larvae grow.

\section{Materials and methods}

\section{Biological material}

Atlantic cod larvae were obtained from SagaFjord Sea Farm AS, a commercial cod hatchery in west coast of Norway. The broodstock was originally caught in wild at coast of Møre, Norway, and ca. 60 fish (size range 8-14 kg, sex ratio about 50:50 from beginning) were kept in a rearing tank $\left(5 \mathrm{~m}\right.$ in diameter, $\left.35 \mathrm{~m}^{3}\right)$ for 2 years before spawning. They were fed formulated dry feed (Vitalis $17 \mathrm{~mm}$ pellets, Skretting, Bergen, Norway). A simulated natural light regime for the latitude of Bergen $\left(60^{\circ} 25^{\prime} \mathrm{N}\right)$ was utilized, and water temperature was $6.5-8.3^{\circ} \mathrm{C}$ during the spawning season. Eggs were naturally spawned in midMarch 2008, disinfected in 300 ppm glutardialdehyde solution for $10 \mathrm{~min}$, and incubated in 1501 aerated black conical tanks at $6.1-7.4^{\circ} \mathrm{C}$. Hatching $(>50 \%)$ occurred 16 days after fertilization, referred to as day 0 of larval age.

\section{Larval rearing condition}

Newly hatched larvae were transferred to green-painted tanks $\left(3 \mathrm{~m}\right.$ in diameter, $\left.7 \mathrm{~m}^{3}\right)$ stocked with approximately 50 larvae $1^{-1}$. Temperature was $9.6-11.1^{\circ} \mathrm{C}$ (average $10.6^{\circ} \mathrm{C}$ ), and oxygen concentration was kept above $90 \%$ saturation. The light regime was set to $16 \mathrm{~h}$ light and $4 \mathrm{~h}$ dark with a period of $2 \mathrm{~h}$ dawn and dusk, respectively. Algae, Tetraselmis sp., were added to the rearing tank from 1 to 34 days post-hatch (dph) reducing from 20 to 121 once a day. Enriched rotifers, Brachionus plicatilis, were used as live prey and added twice a day at optimal density 6,000 prey $1^{-1}$ from $2 \mathrm{dph}$, increasing to 10,000 prey $1^{-1}$ from $17 \mathrm{dph}$. Enriched Artemia were co-fed with rotifers from $24 \mathrm{dph}$. Weaning (AgloNorse Marine 200-300, 300-500 $\mu \mathrm{m}$, EWOS, Bergen, Norway) was started from 35 dph co-fed with Artemia until the larvae were size-sorted and moved to rearing tanks in the juvenile hall at $54 \mathrm{dph}$.
Sampling

Developing larvae were sampled at the following ages; 1 , $4,11,18,25,32,39,46$, and $53 \mathrm{dph}$ from one of the rearing tanks at the hatchery. The larvae were killed by overdose of metacainum $0.2 \mathrm{~g} \mathrm{l}^{-1}$ and then fixed in Bouin's solution at $4^{\circ} \mathrm{C}$ over night and stored in $70 \% \mathrm{EtOH}$ at $4^{\circ} \mathrm{C}$ until use.

\section{$3 \mathrm{D}$ reconstruction of digestive organs in developing cod}

Standard lengths of fixed larvae were measured from photographs shot with a Nikon ACT-2U on a stereo microscope and Image $\mathbf{J}$ software (NIH, USA). Three good-quality larvae representative of the age at each sampling (stars in Fig. 1) were dehydrated and embedded in Technovit 7100 (Heraeus Kulzer GmbH, Hanau, Germany). Semi-thin $(2 \mu \mathrm{m})$ serial sections were stained with Toluidin blue.

One individual larva (the best sectioned one of three) was used to reconstruct the 3D models for $1,4,11,25,39$, and $53 \mathrm{dph}$ larvae. Every fourth section $(8 \mu \mathrm{m}$ between used sections) was photographed using a Nikon Digital Sight DS-U1 camera mounted on a Zeiss Axioscope 2 Plus microscope. Adobe Photoshop 7.0 was used to convert the colour to grey-scale and reduce the picture resolution and size (Fig. 2). Autoaligner 2.0 software (Bitplane AG, Zurich, Switzerland) was used to align the images. Based on the manually defined contour lines (polygons with nodes) of the digestive organs (Fig. 3), contour surfaces were calculated by the software Imaris 6.2.0. (Bitplane $A G)$. Detailed inspection of the 3D models was done within the software as it is possible to (a) show/hide any of the detected organs, (b) make some/all organs semi-transparent, (c) investigate the model from the inside of the digestive system, (d) selectively cut portions of each 3D model organ, and (e) compare each model to original individual histological slices (orthoslicer/oblique slicer). After generating a surface object, the same software (Imaris MeasurementPro) automatically calculates a range of statistical parameters including surface area and volume of the different organs.

\section{Scanning electron microscopy (SEM)}

Three larvae at $53 \mathrm{dph}$ fixed in Bouin's solution were prepared for SEM observation. The guts of the larvae were carefully dissected out, sagittally cut in two using a razor blade, postfixed in osmium tetraoxide for $1 \mathrm{~h}$ on ice, washed in distilled water, dehydrated in acetone series, critical-point-dried, and coated with gold. The specimens were examined in a Zeiss Supra 55 VP field emission scanning microscope. 

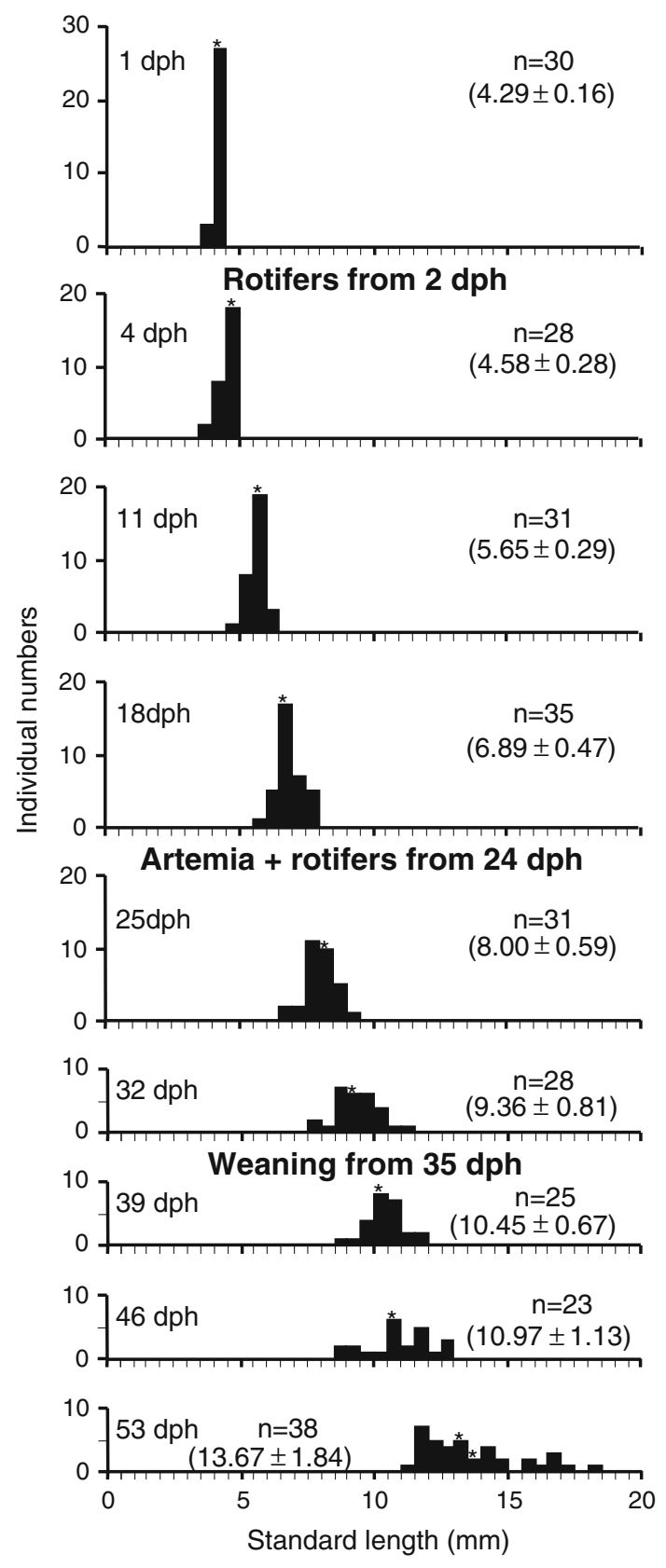

Fig. 1 Standard lengths of sampled larvae after fixation. Feeding items were listed between histograms. Numbers in parentheses is mean $\pm \mathrm{SD}(\mathrm{mm})$. Three individuals from the range of stars were used for histological analysis

\section{Results}

Larval condition and growth

During the rearing period, there was very low mortality and rate of larval deformity. Juvenile production of the season was around 900,000, which was a record production for the hatchery. The materials are therefore regarded as representative larvae in good condition. Standard length of the sampled larvae after fixation is shown in Fig. 1.

Morphological ontogeny of digestive organs

Reconstructed 3D models of the digestive organs from serial histological sections show that important digestive organs such as liver, endocrine and exocrine pancreas, and gallbladder already exist at 1 dph (Figs. 4, 8a, b).

The digestive tract can be subdivided into three parts: a narrow foregut (oesophagus + stomach in later stages), a wide midgut (intestine), and a short hindgut (rectum) (Fig. 5). Pyloric sphincter and ileorectal sphincter were recognizable between the three parts of the gut (Fig. 8a, d, e, g, j, k, l). At $1 \mathrm{dph}$, which was before onset of exogenous feeding, the gut lumen was narrow and straight (Fig. 5). The gut luminal volume increased rapidly and more than 10 times (from 4.3 to $47.3 \mathrm{nl}$ ) after 3 days with rotifer feeding at $4 \mathrm{dph}$ (Fig. 5, Table 1). At $11 \mathrm{dph}$, the posterior part of the midgut started to rotate, and the anterior midgut became wider and slightly curved to the right at $25 \mathrm{dph}$ (Fig. 5). From $39 \mathrm{dph}$, the posterior part of the foregut differentiated into a stomach and increased in size, and gastric glands were also observed on histological sections at this age (Figs. 5, 8g, k, 1). Protrusion of pyloric ceaca started from the most anterior part of the midgut at $39 \mathrm{dph}$ and increased in number and size at $53 \mathrm{dph}$ (Figs. 5, 8g, j). Gut luminal volume at $53 \mathrm{dph}$ was $1,134 \mathrm{nl}$, which was more than 250 times as large as in $1 \mathrm{dph}$ larva $(4.3 \mathrm{nl}$; see Table 1). The gut lumen of $53 \mathrm{dph}$ larva visualized by SEM shows a folded mucosal surface and crowded microvilli on the apical surface (Fig. 6). Since the contour line for the gut inner layer was based on the light microscopic section corresponding to the level of Fig. $6 \mathrm{~b}$, the actual absorption surface including the microvilli surface was not estimated.

Liver was placed under the foregut, but the caudal part of the liver developed along both sides of the foregut during ontogeny. The volume of the liver increased by a factor of more than four from $11 \mathrm{dph}(10.5 \mathrm{nl})$ to $25 \mathrm{dph}$ (48.7 nl) (Table 1). A large yolk-sac was positioned under the gut at $1 \mathrm{dph}$ and decreased in size with development (Fig. 4). Remnant of yolk was found under the liver at 11 $\mathrm{dph}$, but one of the larvae at $18 \mathrm{dph}$ still had yolk remnants in two places: under the liver and under the midgut (data not shown).

Exocrine pancreatic tissue was found on the anterior part of the midgut at $1 \mathrm{dph}$, and it extended to both the right and left sides of the midgut during ontogeny (Fig. 4). Following the gut rotation, the pancreas elongated along the midgut at 39 and $53 \mathrm{dph}$ (Fig. 7). The volume of the pancreas increased by a factor of almost four from $11 \mathrm{dph}$ 
Fig. 2 Examples of serial sections of a 25 dph larva. Section no. 10 is from the right side of the body and no. 90 is from the left side
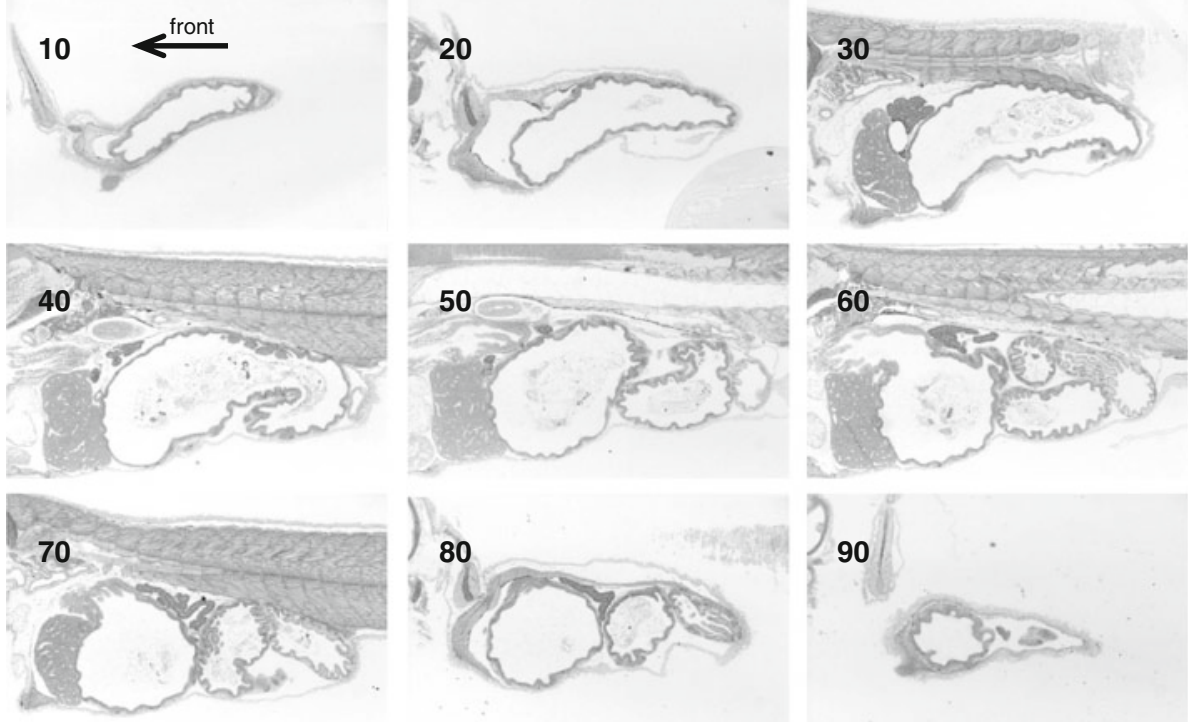

80

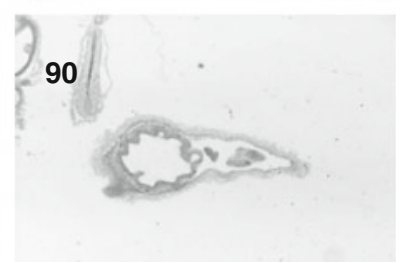

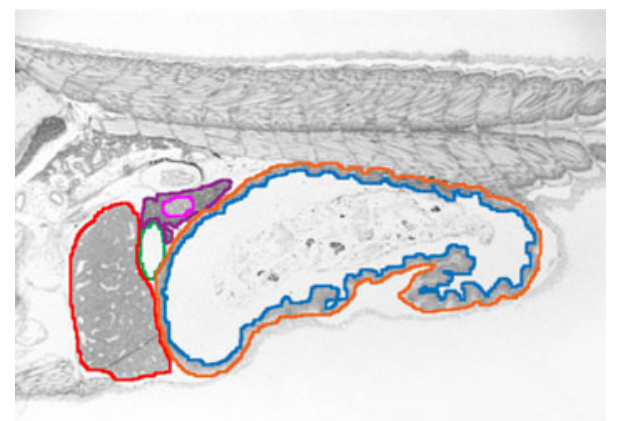

Fig. 3 An example of the drawing process in 25 dph larva section No. 35. Outlines of the digestive organs are drawn in different colours. Orange outer layer of digestive tract, blue inner layer of digestive tract (gut lumen), red liver, green gallbladder, purple pancreas, pink islet of Langerhans. The yolk-sac in younger larvae is coloured yellow

$(2.7 \mathrm{nl})$ to $25 \mathrm{dph}(10.6 \mathrm{nl})$ and almost six from $39 \mathrm{dph}$ (20.6 nl) to $53 \mathrm{dph}(118.2 \mathrm{nl})$ (Table 1).

With regards to the endocrine pancreas, there was only one clearly distinguishable islet of Langerhans in the right side of the pancreas from 1 dph until 39 dph (Figs. 4, 7, 8b, f), while larva at $53 \mathrm{dph}$ had one large and eight small islets of Langerhans (Figs. 7, 8n, o). The large islet was located in the anterior part of the pancreas close to the gallbladder, but the other smaller satellite islets were scattered in the more distal part of the pancreas. These smaller islets seemed to be located close to and along blood vessels. Several smaller parts of the endocrine pancreases may not have been detected during the 3D modelling/rendering, since some clusters of a few cells that had the same characters as endocrine pancreas could be histologically identified in the exocrine part of the pancreas. The volume of the endocrine pancreas increased by a factor of almost three from $11 \mathrm{dph}(0.14 \mathrm{nl})$ to $25 \mathrm{dph}(0.32 \mathrm{nl})$ and more than four from $39 \mathrm{dph}(0.80 \mathrm{nl})$ to $53 \mathrm{dph}(3.56 \mathrm{nl})$ (Table 1).

Gallbladder was also observed the right side of the body close to the largest islet of Langerhans (Figs. 4, 7, 8b, f). The volume of the gallbladder increased by a factor of 12 from $11 \mathrm{dph}(0.1 \mathrm{nl})$ to $25 \mathrm{dph}(1.2 \mathrm{nl})$ (Table 1). The pancreatic duct and the bile duct opened close to each other into the lumen at the median plane of the most anterior midgut (Figs. 7, 8i, m).

These 3D models are available as electronic supplementary materials (ESM) 1-14, which can be viewed and rotated freely by moving a mouse with left-click to better visualize and study the structures of the organs.

\section{Discussion}

This is the first study to show the development of digestive organs in teleosts as 3D models. The 3D models will not only help to understand the morphology of digestive organs better, but also provide a deeper consideration on mechanisms of feeding and digestive physiology during the ontogeny. The software used in the present study permits real-time spatial interaction, i.e. rotation, translation, and zooming both from outside and from within the model (see examples in the enclosed ESM), and the 3D models show the direction of gut rotation, entrances of the bile and pancreatic ducts, and spatial positioning of the organs in relation to each other. Pancreas is not located on one side of the body but on both the left and right sides, lying on the anterior part of the midgut in the early larval stages and developing between the posterior parts of the midgut that is highly coiled. In general, the teleost pancreas is known to 

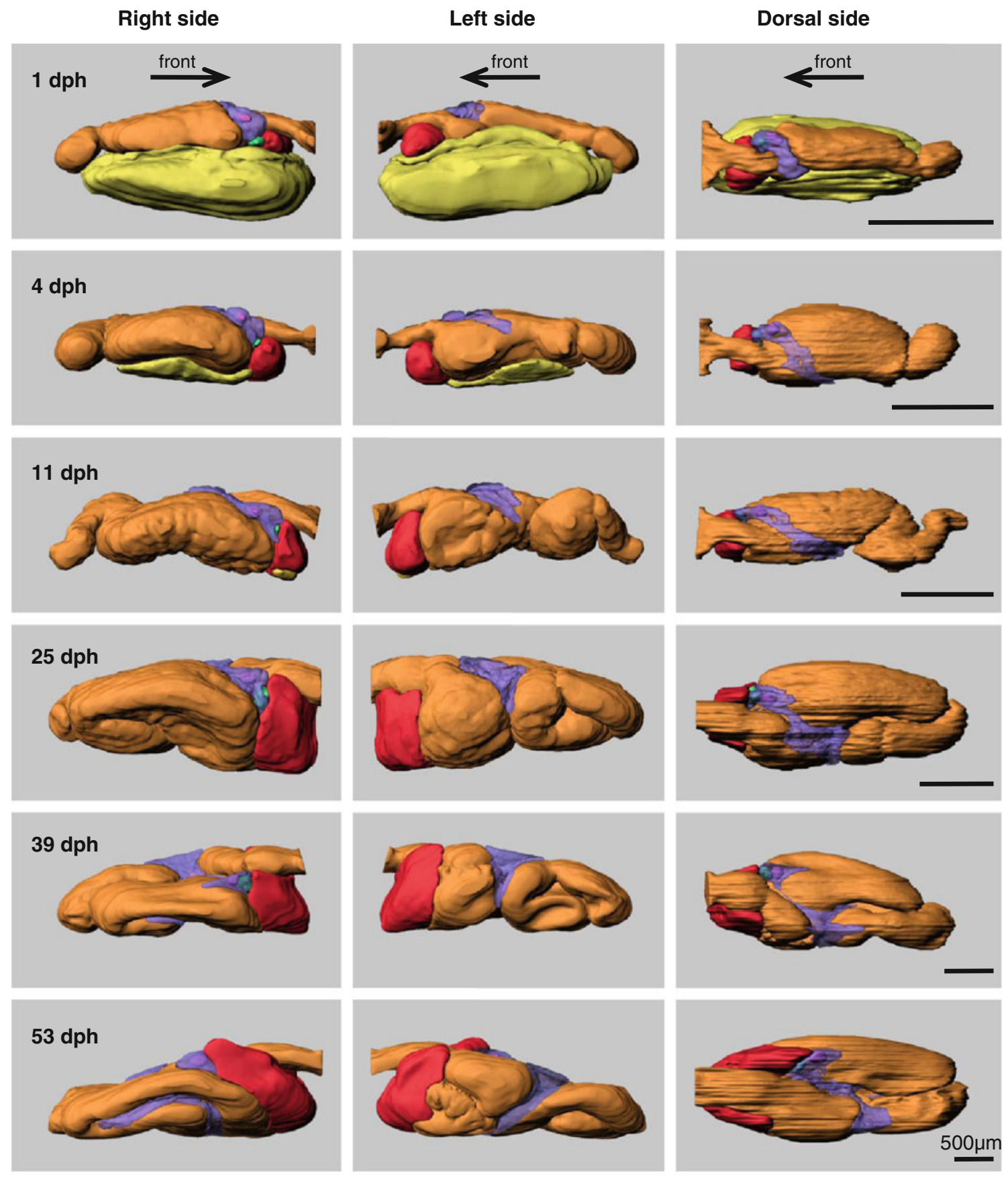

Fig. 4 Ontogeny of the digestive organs in Atlantic cod larvae. 3D models were reconstructed from serial histological sections using Imaris software. The digestive organs are shown from three angles; right, left, and dorsal side. Arrows show the direction of the front

be a diffused organ (Tanaka 1973), but the current 3D models reveal that although pancreas at $53 \mathrm{dph}$ cod is branched and elongated in all directions, it is still connected as one organ and has not formed hepatopancreas even in the oldest larvae. This feature is quite difficult to be interpreted only from the histological sections, and it illustrates the usefulness of 3D models. The models also (mouth). Orange outer layer of digestive tract, red liver, green gallbladder, purple pancreas, pink islet of Langerhans, yellow yolksac. Transparent colour is used for exocrine pancreas (purple) in order to show islets of Langerhans (pink) and gallbladder (green)

visualize the close contact between the exocrine pancreas and the midgut. This implication could be important for better interpretation of studies that deal with gut morphology and digestive physiology. One of the examples is Hartviksen et al. (2009), which described the expression of the hormone, cholecystokinin (CCK), in the digestive tract of developing Atlantic cod larvae. If these results are 

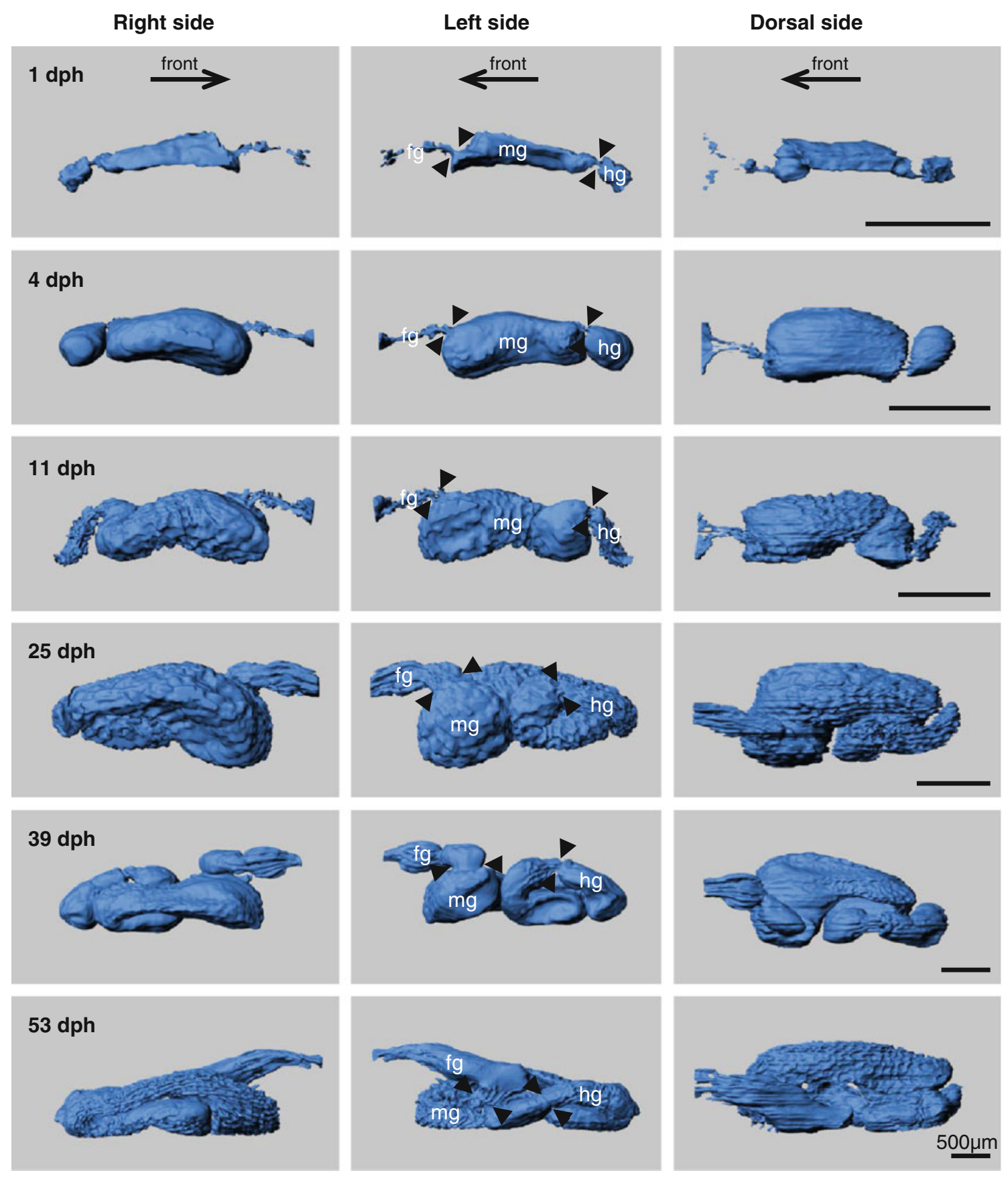

Fig. 5 Ontogeny of the gut lumen represented by the gut inner layer (facing the lumen) of the digestive tract (blue) in Atlantic cod larvae. 3D models were reconstructed from serial histological sections using Imaris software. The digestive tract is seen from three angles; right,

combined with 3D models to show the spatial position of the enteroendocrine cells and the exocrine pancreas, one of the target organs for CCK, this could enhance the functional interpretation. Our 3D models show that pancreas lobes are branched and have very close contact along the entire length of the midgut (Fig. 7) that may shorten transfer distance for CCK and therefore response time of left, and dorsal side. Arrows show the direction of the front (mouth). Arrow heads point to position of sphincters between the foregut and midgut or between the midgut and hindgut. $f g$ foregut, $m g$ midgut, $h g$ hindgut

the hormone. Also, a spatial description of the CCK receptor expression in the pancreatic tissue will add to this understanding. More detailed information about the development and anatomy of digestive organs in Atlantic cod larvae is available from earlier studies (Kjørsvik et al. 1991; Pedersen and Falk-Petersen 1992; Morrison 1993; Hunt von Herbing et al. 1996). 
Table 1 Volumes and surface areas of the digestive organs were calculated from the 3D models by Imaris MeasurementPro (for volume, $1 \mathrm{nl}=10^{6} \mu \mathrm{m}^{3}$ )

\begin{tabular}{|c|c|c|c|c|c|c|}
\hline & $1 \mathrm{dph}$ & $4 \mathrm{dph}$ & $11 \mathrm{dph}$ & $25 \mathrm{dph}$ & $39 \mathrm{dph}$ & $53 \mathrm{dph}$ \\
\hline Gut outer layer (1) (nl) & 14.81 & 64.13 & 97.87 & 357.07 & 710.78 & 2107.59 \\
\hline Gut outer layer $\left(10^{6} \mu \mathrm{m}^{2}\right)$ & 0.57 & 1.27 & 1.79 & 4.44 & 7.11 & 17.38 \\
\hline Gut inner layer $^{\mathrm{a}}(2)(\mathrm{nl})$ & 4.28 & 47.33 & 63.82 & 245.93 & 507.26 & 1134.27 \\
\hline Gut inner layer $\left(10^{6} \mu \mathrm{m}^{2}\right)$ & 0.31 & 1.01 & 1.76 & 5.30 & 6.89 & 17.91 \\
\hline$(1)-(2)^{\mathrm{b}}(\mathrm{nl})$ & 10.53 & 16.81 & 34.04 & 111.14 & 203.52 & 973.32 \\
\hline Liver (nl) & 2.48 & 5.21 & 10.50 & 48.67 & 128.53 & 416.19 \\
\hline Pancreas (nl) & 1.20 & 1.51 & 2.69 & 10.62 & 20.64 & 118.22 \\
\hline Islets of langerhans (nl) & 0.07 & 0.10 & 0.14 & 0.32 & 0.80 & 3.56 \\
\hline Gallbladder (nl) & 0.08 & 0.08 & 0.10 & 1.20 & 1.90 & 4.35 \\
\hline
\end{tabular}

${ }^{a}$ Gut luminal volume

${ }^{\mathrm{b}}$ Epithelial volume

Compared to growth data of Atlantic cod larvae fed zooplankton at the same temperature (ca. $10^{\circ} \mathrm{C}$ ) (Otterlei et al. 1999), our larvae had a lower growth rate. This can partly be explained by shrinkage, since the larvae were measured after fixation and were therefore probably smaller than their actual size. It is known that natural zooplankton-fed larvae show high growth rate compared to rotifer-fed larvae (Otterlei et al. 1999; Finn et al. 2002; Imsland et al. 2006). The underlying reason for the phenomenon is not completely understood, but it is generally explained by the fact that copepods are the natural feed for the cod larvae and under optimal conditions contain all the essential nutrients and minerals necessary for larval development and growth (Hamre et al. 2008; van der Meeren et al. 2008). However, the batch used in the present study did not show any deformities or high mortality, their digestive organs had normal development, and their digestive capacity permitted the processing and absorption of formulated diets at the time of weaning, which indicates that larvae were in good condition even though they grow more slowly.

In early larval stages before a functional stomach with gastric glands develops, the anterior part of the midgut increases significantly the luminal volume into a bulb-like structure (Fig. 5) and appears to play a role as a storage compartment. Functionally, this bulb slows down food transit in this region while permitting efficient mixing with pancreatic and bile secretions. In later larval stages, the stomach develops not from the anterior part of the midgut but from the posterior part of the foregut (also known as stomach anlage) as described by Pedersen and FalkPetersen (1992). The bulb-like anterior part of the midgut was sometimes been regarded as a stomach in earlier studies. However, since the columnar cells with a brush border can be observed in this area and the bile and pancreatic ducts open in the very anterior part of the midgut, which suggests that digestion in this segment operates at alkaline $\mathrm{pH}$, as shown in the Japanese flounder (Paralichthys olivaceus) (Rønnestad et al. 2000), this is not compatible with features of a stomach but should be categorized as a part of the intestine (or anterior part of the midgut).

In the present study, the stomach was first identified at $39 \mathrm{dph}$ on the basis of the presence of gastric glands, and it was still under development at $53 \mathrm{dph}$. At this time, several short pyloric caeca were also observed. Pedersen and FalkPetersen (1992) observed gastric glands in cod larvae of around 18-20 mm, which is much larger than in this study where gastric glands could be seen at $39 \mathrm{dph}$ in larvae ca.
Fig. 6 Gut lumen of Atlantic cod larva at $53 \mathrm{dph}$ taken by SEM. a Gross morphology of a part of the midgut, $\mathbf{b}$ gut lumen magnified part in $\mathbf{a}, \mathbf{c}$ magnified microvilli in light grey part in $\mathbf{b}$, d side view of magnified microvilli in dark grey part in $\mathbf{b}$

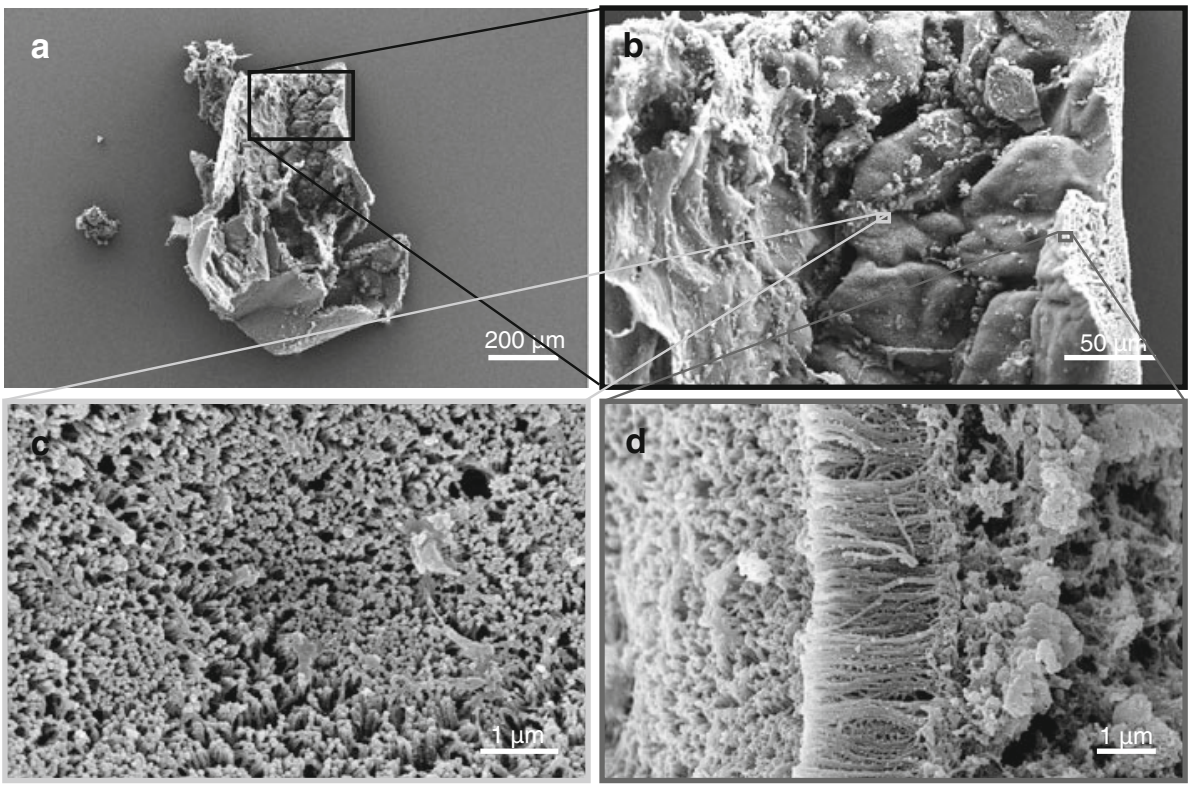


Fig. 7 Ontogeny of the pancreas (60\% transparent purple) in Atlantic cod larvae. The digestive organs are seen from front-left-dorsal side. Islets of Langerhans (pink) and gallbladder (green) are seen in the pancreas. Pancreas creeps in between the crevices of the digestive tract (90\% transparent orange) during development.

Note that pancreas and gallbladder ducts both enter the lumen at median plane of the anterior midgut (arrows)
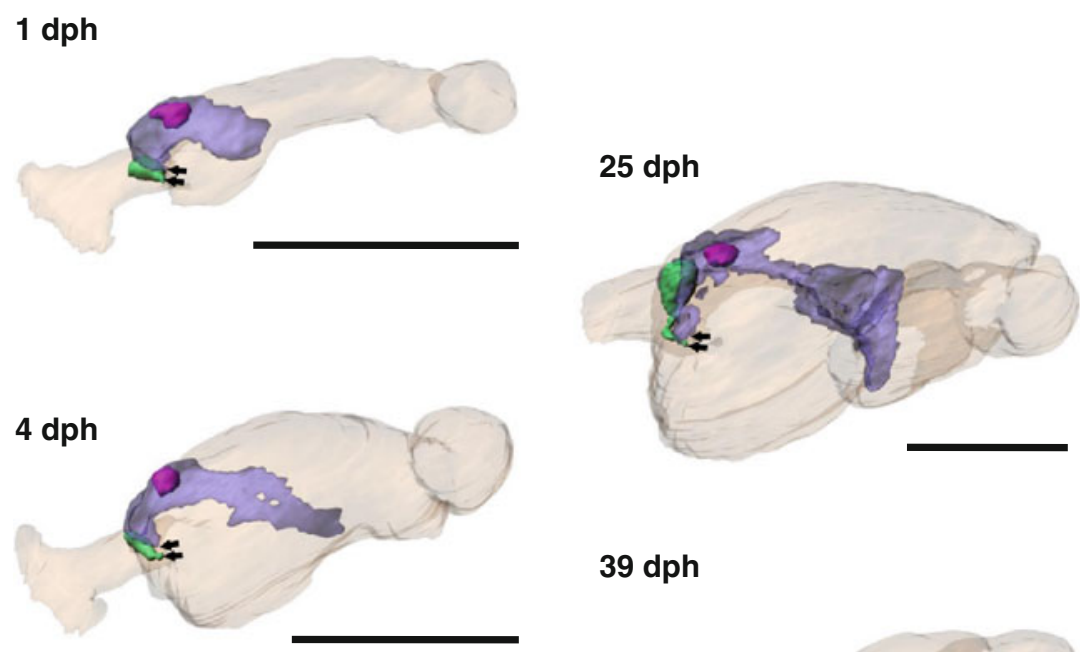

$39 \mathrm{dph}$
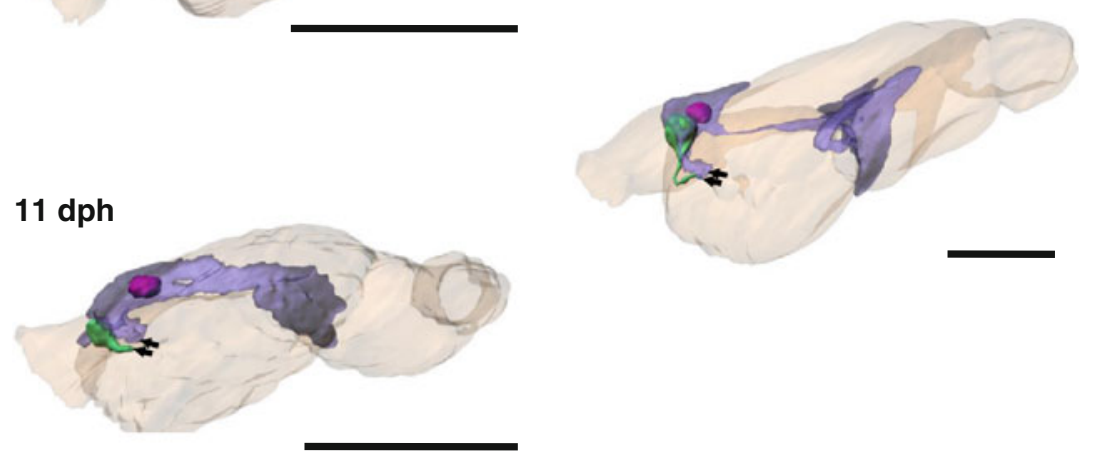

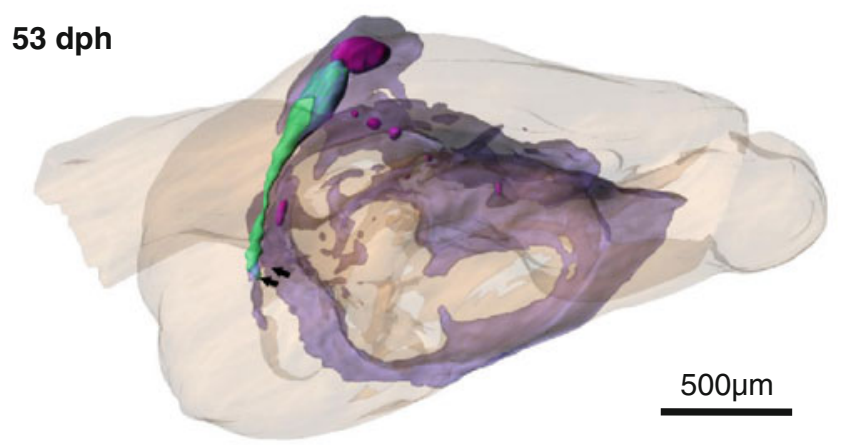

$10 \mathrm{~mm}$ long. This may be the result of nutritional and environmental differences between the studies; larvae were fed natural zooplankton in enclosure system in the former report, while larvae were fed enriched rotifers at land-based commercial tank systems in the present study. This is yet another example of the fact that larval size does not necessarily indicate the developmental stage of digestive organs (Hunt von Herbing et al. 1996). Taking the shrinkage after fixation into consideration, the onset of stomach development in approximately $10 \mathrm{~mm}$-long larvae could be expected, since both metamorphosis and cannibalism of Atlantic cod are known to start at a size of around $12 \mathrm{~mm}$ (Brown et al. 2003). Perez-Casanova et al. (2006) identified gastric glands by histological observation at
25 dph, but pepsinogen was not detected before 35 dph by in situ hybridization and not before 45 dph by RT-PCR. The presence of the gastric glands does not necessarily imply the presence of pepsin digestion. However, the weaning started at $35 \mathrm{dph}$ in the present study seemed appropriate and reasonable, taking into account the development of the digestive capacity of these larvae.

The volume of organs in interest was easily assessed by the software. Although not directly comparable, due to age differences, the sizes for liver and intestinal volumes of cod larvae in the present report support results based on stereological analysis on histological sections on $45 \mathrm{dph}$ cod larvae (Wold et al. 2009). The current data (Table 1) clearly shows that the digestive tract and the associated 

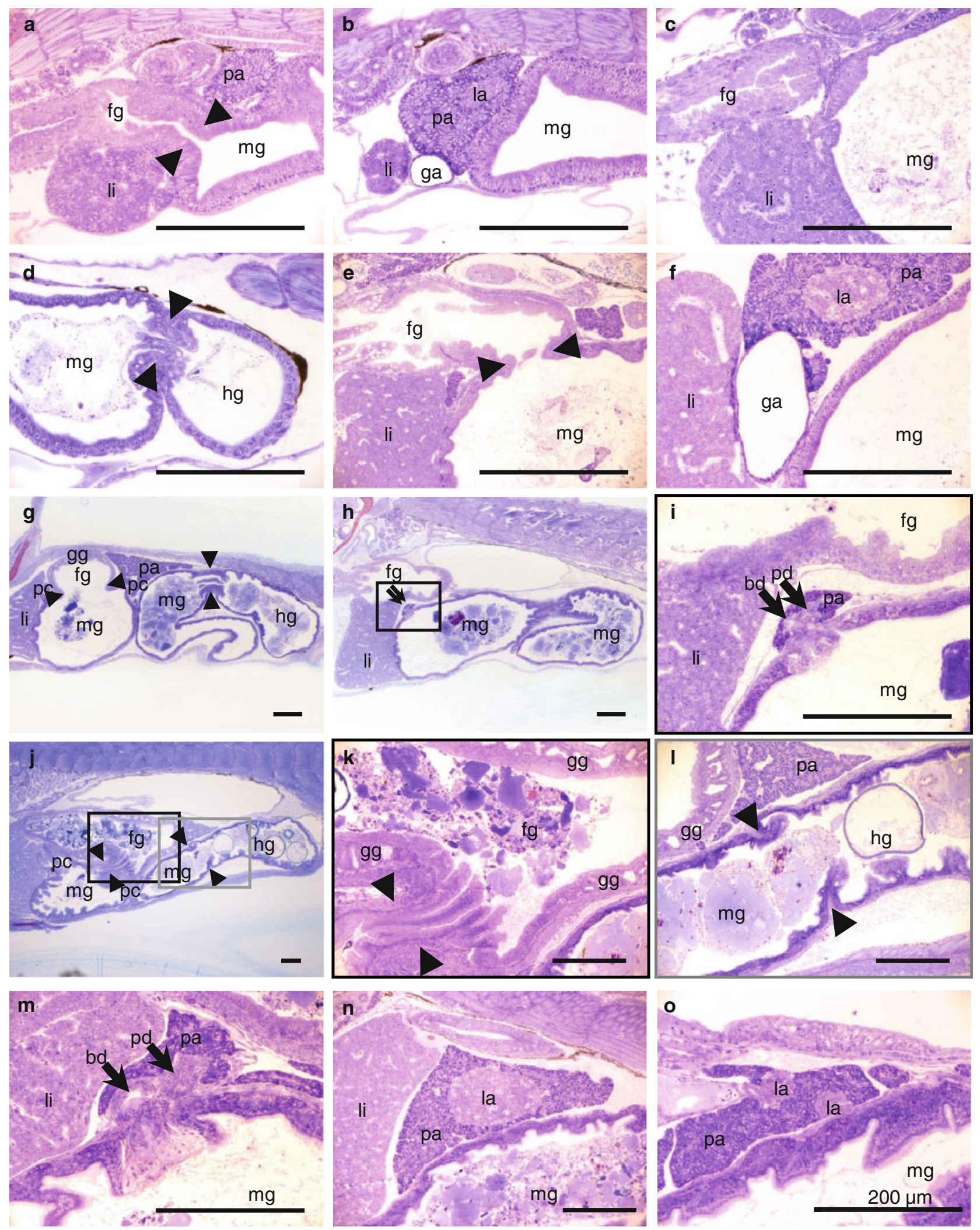

Fig. 8 Histology of digestive organs of Atlantic cod larvae at different ages. a, b $1 \mathrm{dph}, \mathbf{c}, \mathbf{d} 4 \mathrm{dph}$, e, f $25 \mathrm{dph}, \mathbf{g}-\mathbf{i} 39 \mathrm{dph}$, and j-n 53 dph. Arrow heads point to sphincters between the foregut and midgut or between the midgut and hindgut. Arrows point to bile duct $(b d)$ or pancreatic duct $(p d) . f g$ foregut, $g a$ gallbladder, $g g$ gastric gland, $h g$ hindgut, $l a$ islets of Langerhans, li liver, $m g$ midgut, $p a$ pancreas, $p c$ pyloric caeca 
organs exhibit allometric changes during ontogeny of Atlantic cod. This is seen from differences in terms of ratios of dimensions of the various organs, and it permits some rough assessments of morphometric scaling during ontogeny that might have functional implications for the physiology of the developing cod larvae. The relative volumes of pancreas and liver appeared to be declining from $48 \%$ at first feeding ( $1 \mathrm{dph}$ ) to $16 \%$ at $39 \mathrm{dph}$, when the stomach starts to become differentiated. This suggests the importance of the pancreatic digestive enzymes (need for digestive effort/capacity) compared to liver metabolic enzymes (post-absorptive nutrient processing) in the early agastric stages. The ratio of the volumes of the pancreas and the gut lumen was relatively stable, which can serve as a very rough indication that digestive capacity is matched to the material that is to be digested. The ratio of volumes for the endocrine to exocrine pancreas remained fairly constant and below 5\%, which suggests that their relative quantitative importance may be maintained. One limitation of the interpretation of the data is obviously the lack of concurrent physiological data for enzymes, hormones, and metabolism in the digestive tract and adjacent organs, but the numbers provided serve as a basis for further studies of anatomical and physiological scaling of the digestive system and processes during ontogeny. These data are also useful for better understanding of metabolic scaling in animals (e.g. Banavar et al. 2002) including Atlantic cod larvae (Finn et al. 2002) as well as scaling of the total delivery capacity of the digestive system to match the changing metabolic and anabolic demands at different body sizes. It should be reemphasized that our volume and area data of organs were calculated on the basis of one individual per data point, which does not permit definitive conclusions to be drawn. 3D reconstruction with the version of the software we used (Imaris 6.2.0) is a time-consuming process and is therefore unsuitable for large-scale quantitative work. However, recent advances in the software allows semi-automatic contour detection, which opens the possibility of larger-scale quantitative/comparative studies, since it can speed up the 3D-model creation process significantly (present work required the manual creation of each contour by the addition of up to several hundred nodes to make a single contour).

There are possibilities for minor artefacts of the alignment and the generating surfaces based on manually drawn contour lines. During the section preparation, semi-thin sections may have stretched out in different manner. Very small parts of organs (e.g. elongated pancreatic tissue) may also have been missed during the drawing/calculation of the contour surface, although particular attention was paid to this detail. The reason for adjacent contour lines not linking (thus not making a surface) is that either (a) they were too far from each other or (b) their shapes were very different.

\section{Conclusions}

With the aid of 3D rendering and analysis software, 3D models of digestive organs were reconstructed from different developmental stages of Atlantic cod. The models visually demonstrates a range of functional features of developing organs including folding of the gut rotation; subdivision of digestive tract by sphincters; location of entrances of bile and pancreatic ducts; the relatively large volume of the anterior midgut; development of stomach and pyloric caeca; ontogeny of pancreas from a compact organ to an elongated and branched organ along the posterior midgut; and one dominant islet of Langerhans until $39 \mathrm{dph}$ while several smaller satellite islets also visible from $53 \mathrm{dph}$. Calculated volumes based on the models reveal that the digestive tract and associated organs exhibit allometric changes during ontogeny. These models will serve as a reference for future functional studies and will permit 3D visualization and interpretation of whole mount in situ analysis, histological sections or drawings, particularly when the larvae develop and the elongated gut becomes more coiled in the peritoneal cavity.

Acknowledgments We thank Dr. E. Otterlei at SagaFjord Sea Farm AS for supplying the material. We also thank Professor H. Kryvi, Professor G. K. Totland, E. S. Erichsen, X. Wang, N. Ellingsen and T. Cieplinska at University of Bergen for histological discussions, teaching SEM, Imaris, and technical assistance. Thanks are also due to Dr. L. Lucas at Bitplane for technical support on Imaris and critical reading of the manuscript. This study was supported by Research Council of Norway projects \#187281 (DGS) and \#199482 (CODE).

Open Access This article is distributed under the terms of the Creative Commons Attribution Noncommercial License which permits any noncommercial use, distribution, and reproduction in any medium, provided the original author(s) and source are credited.

\section{References}

Banavar JR, Damuth J, Maritan A, Rinaldo A (2002) Supply-demand balance and metabolic scaling. Proc Natl Acad Sci USA 99:10506-10509. doi:10.1073/pnas.162216899

Brown JA, Minkoff G, Puvanendran V (2003) Larviculture of Atlantic cod (Gadus morhua): progress, protocols and problems. Aquaculture 227:357-372. doi:10.1016/S0044-8486(03)00514

Engelsen R, Asche F, Skjennum F, Adoff G (2004) New species in aquaculture: some basic economic aspects. In: Moksness E, Kjørsvik E, Olsen Y (eds) Culture of cold-water marine fish. Blackwell, Oxford, pp 487-515

Finn RN, Rønnestad I, van der Meeren T, Fyhn HJ (2002) Fuel and metabolic scaling during the early life stages of Atlantic cod 
Gadus morhua. Mar Ecol Prog Ser 243:217-234. doi: $10.3354 /$ meps 243217

Hamlin HJ, Hunt von Herbing I, Kling LJ (2000) Histological and morphological evaluations of the digestive tract and associated organs of haddock throughout post-hatching ontogeny. J Fish Biol 57:716-732. doi:10.1006/jfbi.2000.1347

Hamre K, Srivastava A, Rønnestad I, Mangor-Jensen A, Stoss J (2008) Several micronutrients in the rotifer Brachionus sp may not fulfil the nutritional requirements of marine fish larvae. Aquac Nutr 14:51-60. doi:10.1111/j.1365-2095.2007.00504.x

Hartviksen MB, Kamisaka Y, Jordal AEO, Koedijk RM, Rønnestad I (2009) Distribution of cholecystokinin-immunoreactive cells in the gut of developing Atlantic cod Gadus morhua L. larvae fed zooplankton or rotifers. J Fish Biol 75:834-844. doi: 10.1111/j.1095-8649.2009.02325.x

Hunt von Herbing I, Boutillier RG, Miyake T, Hall BK (1996) Effects of temperature on morphological landmarks critical to growth and survival in larval Atlantic cod (Gadus morhua). Mar Biol 124:593-606. doi:10.1007/BF00351041

Imsland AK, Foss A, Koedijk R, Folkvord A, Stefansson SO, Jonassen TM (2006) Short- and long-term differences in growth, feed conversion efficiency and deformities in juvenile Atlantic cod (Gadus morhua) startfed on rotifers or zooplankton. Aquac Res 37:1015-1027. doi:10.1111/j.1365-2109.2006.01523.x

Kjørsvik E, Meeren VDT, Kryvi H, Arnfinnson J, Kvenseth PG (1991) Early development of the digestive tract of cod larvae, Gadus morhua L., during start-feeding and starvation. J Fish Biol 38:1-15. doi:10.1111/j.1095-8649.1991.tb03086.x

Kvåle A, Mangor-Jensen A, Moren M, Espe M, Hamre K (2007) Development and characterisation of some intestinal enzymes in Atlantic cod (Gadus morhua L.) and Atlantic halibut (Hippoglossus hippoglossus L.) larvae. Aquaculture 264:457-468. doi: 10.1016/j.aquaculture.2006.12.024

Mangor-Jensen A, Øiestad V, van der Meeren T, Lein I, Harboe T, Opstad I, Øie G, Rainuzzo J, Evajemo JO, Reitan KI, Terjesen BF (2007) From extensive to intensive production of marine fish. In: Thomassen M, Gudding R, Norberg B, Jørgensen L (eds) Aquaculture research: from cage to consumption. The Research Council of Norway, Oslo, pp 80-99

Morrison CM (1993) Histology of the Atlantic cod, Gadus morhua: An atlas. Part four. Eleutheroembryo and larva. National
Research Council of Canada and Department of Fisheries and Oceans, Ottawa

Otterlei E, Nyhammer G, Folkvord A, Stefansson SO (1999) Temperature- and size-dependent growth of larval and early juvenile Atlantic cod (Gadus morhua): a comparative study of Norwegian coastal cod and northeast Arctic cod. Can J Fish Aquat Sci 56:2099-2111. doi:10.1139/cjfas-56-11-2099

Pedersen T, Falk-Petersen IB (1992) Morphological changes during metamorphosis in cod (Gadus morhua L.), with particular reference to the development of the stomach and pyloric caeca. J Fish Biol 41:449-461. doi:10.1111/j.1095-8649.1992.tb02 673.x

Perez-Casanova JC, Murray HM, Gallant JW, Ross NW, Douglas SE, Johnson SC (2006) Development of the digestive capacity in larvae of haddock (Melanogrammus aeglefinus) and Atlantic cod (Gadus morhua). Aquaculture 251:377-401. doi:10.1016/j. aquaculture.2005.06.007

Rønnestad I, Dominguez RP, Tanaka M (2000) Ontogeny of digestive tract functionality in Japanese flounder, Paralichthys olivaceus studied by in vivo microinjection: $\mathrm{pH}$ and assimilation of free amino acids. Fish Physiol Biochem 22:225-235. doi:10.1023/ A:1007801510056

Rosenlund G, Halldórsson Ó (2007) Cod juvenile production: research and commercial development. Aquaculture 268:188-194. doi: 10.1016/j.aquaculture.2007.04.040

Tanaka M (1973) Studies on the structure and function of the digestive system of teleost larvae. Dissertation, Kyoto University, Kyoto

van der Meeren T, Olsen RE, Hamre K, Fyhn HJ (2008) Biochemical composition of copepods for eveluation of feed quality in production of juvenile marine fish. Aquaculture 274: 375-397. doi:10.1016/j.aquaculture.2007.11.041

Wold P-A, Hoehne-Reitan K, Rainuzzo J, Kjørsvik E (2008) Allmetric growth and functional development of the gut in developing cod Gadus morhua L. larvae. J Fish Biol 72:1637-1658. doi:10.1111/j.1095-8649.2008.01831.x

Wold P-A, Hoehne-Reitan K, Cahu CL, Infante JZ, Rainuzzo J, Kjørsvik E (2009) Comparison of dietary phospholipids and neutral lipids: effects on gut, liver and pancreas histology in Atlantic cod (Gadus morhua L.) larvae. Aquac Nutr 15:73-84. doi:10.1111/j.1365-2095.2008.00569.x 